\title{
The Effect of Regular Primary Care Utilization on Long-Term Glycemic and Blood Pressure Control in Adults With Diabetes
}

\author{
Julia J. Smith, MS, Matthew D. Berman, PhD, Vanessa Y. Hiratsuka, PhD, MPH, \\ and Rosyland R. Frazier, MS
}

Purpose: Complications of diabetes mellitus (DM) can be reduced with regular preventive care and guidance on self-management. We investigated whether regular primary care utilization could improve glycemic control and blood pressure control among American Indian/Alaska Native people with DM.

Methods: Patient characteristics, risk factors, and health outcomes were identified from electronic health records of a cohort of 2138 adults with DM who received care between 1995 and 2010 from Southcentral Foundation, a tribal provider. Bivariate probit regression models estimated the probability of glycemic control and blood pressure control as functions of regular primary care, risk factors, and access factors, while taking into account potential bias arising from voluntarily choosing to seek primary care services.

Results: Regular primary care was associated with an $89 \%$ increased likelihood of blood pressure control (95\% confidence interval [CI], 59-118\%) and 177\% increased likelihood of glycemic control (95\% CI, 123-222\%). Increasing the distance by 10 miles to primary care services reduced the likelihood of regular primary care by $3.7 \%(95 \% \mathrm{CI},-2.9 \%$ to $-4.6 \%)$.

Conclusions: Regular primary care utilization over 16 years was associated with higher rates of blood pressure control and glycemic control for adults with DM. People living closer to primary care services had a better chance of improved outcomes. (J Am Board Fam Med 2015;28:28-37.)

Keywords: Diabetes Mellitus, Indigenous Health Services, Primary Health Care

Complications of diabetes mellitus (DM) can be reduced with regular preventive care and guidance on self-management of the disease. Conversely, patients who are not regularly screened by a health care provider for hemoglobin A1c (HbA1c) concentrations, blood pressure, and lipids are at risk of developing health complications that can adversely affect quality of life, result in costly emergency and

This article was externally peer reviewed.

Submitted 20 December 2013; revised 2 August 2014; accepted 6 August 2014.

From the Research Department, Southcentral Foundation, Anchorage, AK (JJS, VYH); and the Institute of Social and Economic Research, University of Alaska-Anchorage (MDB, RRF).

Funding: This work was supported by the US Agency for Healthcare Research and Quality (grant no. 1R18HS019154-01).

Conflict of interest: none declared.

Corresponding author: Matthew D. Berman, $\mathrm{PhD}$, Institute of Social and Economic Research, University of AlaskaAnchorage, 3211 Providence Dr., Anchorage, AK 99508 (E-mail: matthew.berman@uaa.alaska.edu). tertiary health care utilization, and contribute to premature death. ${ }^{1,2}$ Coordinated patient-centered primary care can improve health outcomes for patients with DM, and access to primary care providers can reduce emergency department use, hospitalizations, morbidity, mortality, and cost. ${ }^{3,4}$

The patient-centered medical home (PCMH) model of care includes tenets that support better care for patients with chronic conditions such as DM, including advanced access to health care providers; coordinated care across primary, specialty, and tertiary care; improved health technology systems; and continuity of care with the primary care providers. ${ }^{5}$ Under the PCMH model of care, patients with DM are less likely to miss screenings; providers are able to tailor self-management plans to individual patients; providers coordinate care and are aware of adverse health outcomes; and patients are less likely to develop complications. ${ }^{6,7}$ Some studies have shown improved outcomes for 
patients with DM receiving care after implementation of components of the PCMH model. ${ }^{4,8-14}$

Southcentral Foundation (SCF) is an Alaska Native (AN) nonprofit health corporation providing prepaid primary care for 60,000 AN people living in Anchorage, the Matanuska-Susitna Valley, and the surrounding rural villages of south-central Alaska. In partnership with the Alaska Native Tribal Health Consortium (ANTHC), SCF also comanages the AN Medical Center, serving 120,000 AN/American Indian (AI) people statewide. ${ }^{15}$ SCF's service population includes the 229 federally recognized tribes of Alaska as well as a large proportion of the 336 federally recognized tribes in the contiguous United States. In 1997 SCF assumed ownership of primary care services for AI/AN people of south-central Alaska and in 1999 transformed the delivery of care using key components of the PCMH model: matching patients with an integrated, comprehensive care team; enhancing access to health care services; and coordinating care by integrated primary care teams. ${ }^{16}$ SCF's AI/AN patients are both customers and owners of the health care system and thus are called "customer-owners" rather than patients.

The PCMH model was adopted at SCF in part to address observed AI/AN health disparities compared with the US population. For instance, the Indian Health Service reports a higher mortality rate from DM (177\% higher) and chronic lower respiratory diseases (59\% higher) for AI/AN than other Americans. ${ }^{17}$ Despite recent improvements in health status, life expectancy for the south-central Alaska AI/AN population remains 8 years shorter, obesity rates are one-third higher, and adult smoking prevalence is double that of the white US population. ${ }^{18}$

Nationally, AI/AN people bear a disproportionate burden of diabetes. ${ }^{19,20}$ Since its inception, the Special Diabetes Program for Indians, established as part of the Balanced Budget Act of 1997, has provided to SCF and ANTHC federal grant funds to conduct primary, secondary, and tertiary prevention activities. Diabetes prevention activities at SCF included hiring health care staff to support integrated care teams (ie, nutritionists and case managers) and providing public health education classes (ie, promotion of healthy diet and exercise, smoking cessation). ${ }^{19,21}$ Primary care services and health education classes are offered to customerowners at the Anchorage Native Primary Care
Center (ANPCC) in Anchorage. Since 2005, primary care services also have been offered at the Valley Native Primary Care Center (VNPCC) in Wasilla, 45 miles from the ANPCC. The VNPCC primarily serves customer-owners living in the Matanuska-Susitna Valley, directly north of Anchorage.

In this effort we aimed to assess the effect of primary care utilization on glycemic control and blood pressure control for a cohort of customerowners with DM who received care from SCF. The study period spanned 16 years, including years both before and after implementation of PCMH components. We hypothesized that regular primary care was associated with an increased likelihood of both blood pressure control and glycemic control after controlling for other relevant factors. A challenge to testing hypotheses about the effects of primary care is that people who regularly use primary care may differ in systematic ways from those who do not, potentially creating a bias. Techniques that could address this bias are well known but are rarely used in the literature evaluating primary care.

\section{Methods}

This was a cohort study of all SCF customer-owners and Indian Health Service Anchorage service area enrollees who were age 21 or older, determined to have DM before the last available medical record observation, and received care during part or all of the study period (1995-2010). At least 2 DM diagnoses (International Classification of Diseases, 9th edition, code 250.xx) within a 2-year period or inclusion in the AN Medical Center diabetes registry were required to indicate DM. All measures were queried from the electronic health and billing records used by SCF and ANTHC. The beginning of the study period coincides with the first year for which data were reliably available in the electronic records. Health records extracted for the study could include encounters before the date of first DM diagnosis if the person received this diagnosis after age 21 and was already a customerowner.

\section{Measures}

All measures were aggregated over each quarter (3 months) as presence or absence for binary measures, totals for count measures, and averages for 
other continuous measures, with the exception of using the maximum HbA1c measurement. There were 3 binary outcome measures used in this study. Regular primary care (RPC) utilization was defined by the presence or absence of at least 1 visit every 6 months for 2 consecutive 6-month intervals. This definition was used because individuals with DM need to be seen a minimum of once every 6 months to meet guidelines for the minimal level of preventive care (eg, HbAlc screenings are recommended every 6 months by the American Diabetes Association $\left.^{1}\right)$. To allow new customer-owners time to receive RPC, first-year observations were excluded. Blood pressure control was defined as present if the average blood pressure reading had both systolic $<130 \mathrm{mmHg}$ and diastolic $<80 \mathrm{mmHg}$. The American Diabetes Association published this treatment guideline ${ }^{22}$ in early 2004, in the middle of the study period. Since it is possible that some clinicians may have been treating milder hypertension less aggressively in the early years of the study, a measure of blood pressure control defined as an average blood pressure reading with both systolic $<140 \mathrm{mmHg}$ and diastolic $<90 \mathrm{mmHg}$ and a measure changing from the higher to the lower threshold in 2004 were also considered. Glycemic control was defined as a maximum $\mathrm{HbA} 1 \mathrm{c}<7 \%$ and screening every 6 months, a guideline used for SCF and Indian Health Service quality assurance and improvement efforts. ${ }^{23}$

Quarterly risk factors included age, sex, and duration of DM (calculated from the date of first diagnosis or date in the registry). Baseline risk factors that could change because of primary care were measured at customer-owners' first encounter and include body mass index (BMI), a hypertension index (an indicator of hypertension severity) and a related blood pressure index (a combined indicator of systolic and diastolic measurements; see the Table 2 footnote), smoking status, and smokeless tobacco use status. An additional variable, excess BMI (amount by which BMI exceeds 25), was used to investigate the impact of severe obesity, given the strong skew in BMI values. Other risk factors were calculated as presence in any quarter and included the following: diagnosis of high low-density lipoprotein (International Classification of Diseases, 9th edition, code 272.xx), prescribed insulin, and date of DM onset retrieved from the DM registry (versus the date of first diagnosis). The latter was considered a risk factor because those customer-owners who did not have a first diagnosis in the medical record originally lived in remote regions in Alaska where primary care was not readily available, and thus DM may have progressed differently than in those for whom RPC was available since the onset of DM. Additional variables addressed access to primary care and included a binary variable indicating community of residence in the Matanuska-Susitna borough, a binary variable indicating residence address outside the SCF service area despite an indication of receipt of care at SCF, and distance from community of residence to the nearest primary care center (either the ANPCC or VNPCC).

\section{Statistical Methods}

Hypothesizing that receiving RPC improves outcomes for people with diabetes, including increased likelihood of blood pressure control and glycemic control, is reasonable. However, finding reliable statistical evidence to support this hypothesis is challenging because utilization of primary care is voluntary. For example, individuals with poor health conditions such as high blood pressure or poor glycemic control may have high utilization if they need to see a doctor for prescriptions related to uncontrolled conditions, uncomfortable symptoms of the conditions themselves, or symptoms of comorbid conditions. In these circumstances common statistical methods (eg, logistic regression) might show a higher likelihood of poor health conditions among those receiving RPC. In this scenario the increased likelihood of utilization among those with worse health confounds the ability of a retrospective study to test whether primary care utilization affects health outcomes and potentially leads to biased results. Although the problem of voluntary receipt of primary care could theoretically be addressed via controlled random assignment into groups with differing treatment regimes, a controlled experiment that denies primary care to some participants is neither ethical nor practical.

Another approach is to statistically address the potential correlation in the relationship between primary care utilization and health outcomes. Bivariate probit regression jointly estimates simultaneous equations for the likelihood of each of 2 correlated binary ("presence/absence") outcomes. The procedure automatically adjusts the results to control for the correlation between the 2 outcomes so that the unbiased effect of one outcome on the other can be measured. In this study bivariate pro- 


\begin{tabular}{|c|c|c|c|}
\hline & Observations (n) & Mean (SD) & Percentage \\
\hline \multicolumn{4}{|l|}{ Characteristics of the study population* } \\
\hline \multicolumn{4}{|l|}{ Demographics } \\
\hline Female sex ${ }^{\dagger}$ & 2,138 & - & 59.5 \\
\hline Age & 2,138 & $52.0(14.3)$ & - \\
\hline \multicolumn{4}{|l|}{ Diabetes mellitus } \\
\hline Diagnosis from registry $^{\dagger}$ & 2,138 & - & 53.1 \\
\hline Years since diabetes onset & 2,138 & $1.2(3.0)$ & - \\
\hline \multicolumn{4}{|l|}{ Risk factors } \\
\hline Prescribed insulin ${ }^{\dagger}$ & 1,712 & - & 22.0 \\
\hline Tobacco smoker ${ }^{\dagger}$ & 1,593 & - & 44.0 \\
\hline Smokeless tobacco user ${ }^{\dagger}$ & 1,593 & - & 9.5 \\
\hline High LDL diagnosis ${ }^{\dagger}$ & 1,712 & - & 70.4 \\
\hline Prescribed insulin ${ }^{\dagger}$ & 1,712 & - & 22.0 \\
\hline Body mass index ${ }^{\dagger}$ & 1,845 & $36.2(8.4)$ & - \\
\hline$>25$ (overweight/obese) & 1,841 & - & 93.8 \\
\hline$>30$ (obese) & 1,841 & - & 77.6 \\
\hline Systolic BP & 2,104 & $138.6(21.0)$ & - \\
\hline Diastolic BP & 2,104 & $79.0(12.9)$ & - \\
\hline Hypertension diagnosis $^{\dagger}$ (systolic BP $\geq 140$ or diastolic BP $\geq 90$ ) & 2,104 & - & 50.2 \\
\hline \multicolumn{4}{|l|}{ Access } \\
\hline Distance from clinic (miles) & 2,107 & $7.1(10.5)$ & - \\
\hline Matanuska-Susitna borough resident ${ }^{\dagger}$ & 2,107 & - & 10.2 \\
\hline \multicolumn{4}{|l|}{ Summary statistics of quarterly health care encounters } \\
\hline At least one encounter during the past year ${ }^{\dagger}$ & 56,906 & - & 92.2 \\
\hline Primary care visits that quarter (n) & 56,906 & $2.62(3.32)$ & - \\
\hline HbA1c percentage (most recent measurement) & 52,145 & $7.5(1.8)$ & - \\
\hline Days between HbA1c measurements & 52,145 & $378.0(607.1)$ & - \\
\hline Attended nutrition and exercise education classes & 55,407 & $0.9(4.8)$ & - \\
\hline At least one primary care visit per 6 months in the past year ${ }^{\dagger}$ & 54,572 & - & 78.1 \\
\hline
\end{tabular}

${ }^{*}$ Measured during the first encounter.

${ }^{\dagger}$ Binary measure.

BP, blood pressure; HbA1c, hemoglobin A1c; LDL, low-density lipoprotein; SD, standard deviation.

bit regression was used to estimate simultaneously the probability of blood pressure control and the probability of RPC to investigate the effect of RPC on blood pressure control as an explanatory variable while adjusting for the general correlation between the 2 measures. Additional explanatory variables included risk factors, access factors, and number of nutrition and exercise classes attended. Significant interactions included DM duration and patient age; duration and date of onset based on the DM registry; and BMI and age. Since the data included repeated observations at quarterly intervals, the models included indicators of the quarter and year of each observation to address general changes over time (data not shown).

Similar methods were used to estimate the probability and effect of glycemic control and the prob- ability of RPC, with one important distinction. The equations for glycemic control covered only the period after the official DM diagnosis because systematic determination of glycemic control was expected only after DM onset.

Probit equations are similar to logistic regressions for binary outcomes except for the units of the outcome variable. Logistic regressions predict the log of the odds ratio, whereas probit regressions predict the $z$ score associated with the probability that the outcome is true. Therefore in these results estimated effects are represented as predicted changes in $z$ scores.

One other statistical method used in these analyses should be explained. That the number of nutrition and exercise classes attended could explain health outcomes was expected, and this variable 
Figure 1. Percentage of patients with diabetes mellitus with blood pressure control over time at 2 thresholds: $<140 / 90$ and $<130 / 80 \mathrm{mmHg}$. The clinical standard for diabetes mellitus changed from $140 / 90$ to $130 / 80 \mathrm{mmHg}$ in 2004 .

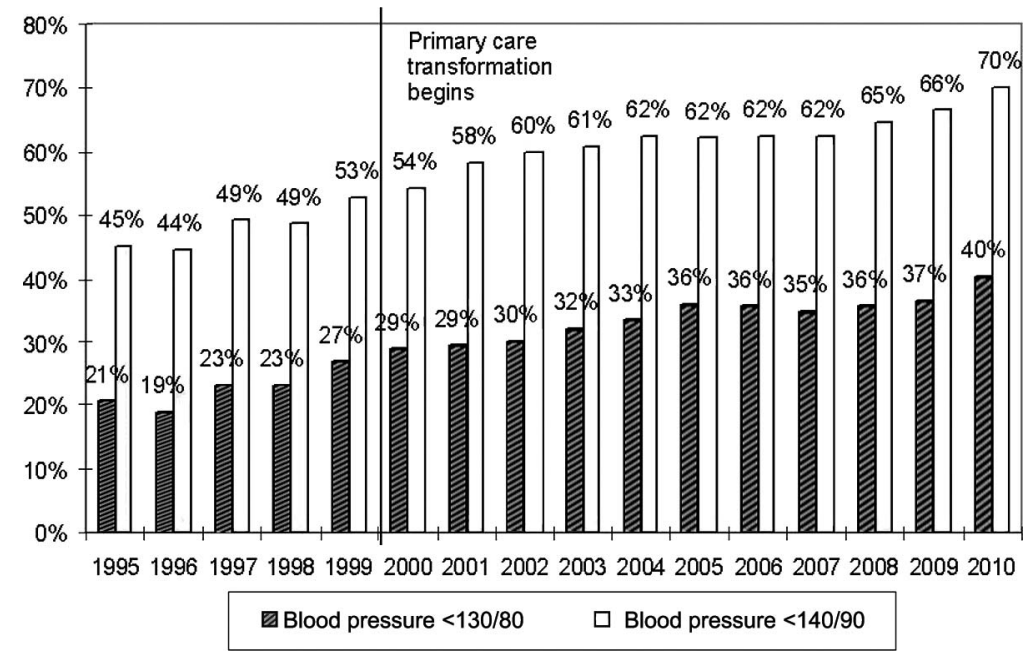

should be included in models. However, customerowners presenting with poor health outcomes may be referred to such classes by their provider, in which case the health outcome influences attendance, confounding the attempt to estimate the effect of attendance on health outcomes. In cases of reverse causation, such as this, instrumental variables can provide unbiased estimates of the effect of education classes on health outcomes. ${ }^{24}$ The instrument used in this analysis was the set of predicted values of a negative binomial regression for the predictive factors (number of education classes attended, estimated with DM risk factors, the total number of classes offered that quarter, and the distance from the customer-owner's community of residence to the location of classes). This instrument was not significant in the model for glycemic control and thus was excluded from that equation.

\section{Results}

The study population was nearly $60 \%$ female, with an average age of 52 years at the first encounter (Table 1). A high proportion of the population exhibited multiple risk factors for DM and its complications. Of participants, 94\% were overweight, and more than three-fourths were obese. About

Figure 2. Glycemic control rates (percentage) over time among patients with $\mathrm{HbA}_{\mathbf{1 c}}<7 \%$ and screened at least once in the past 6 months.

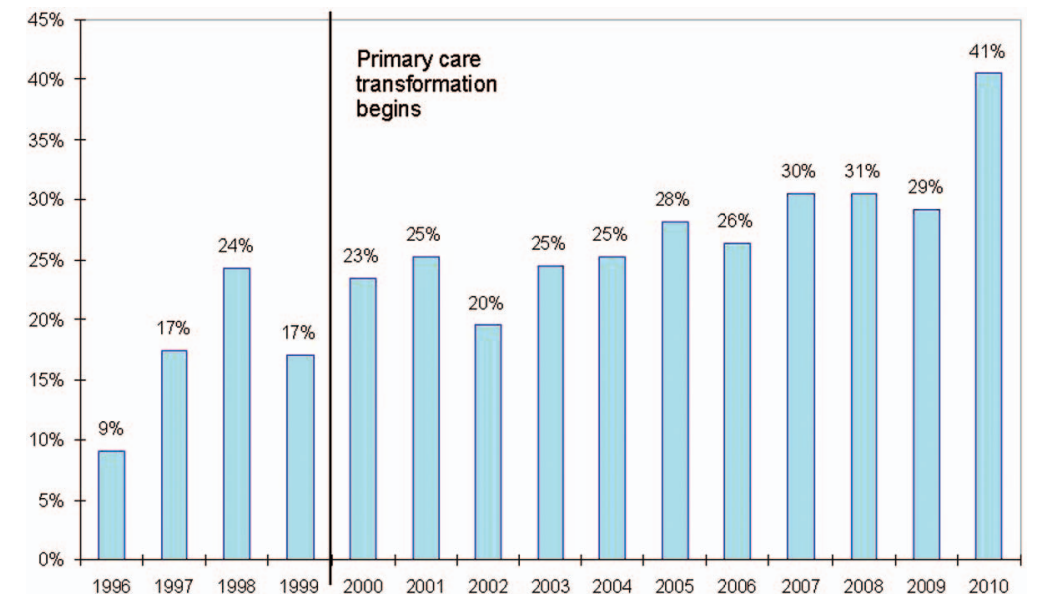


Table 2. Bivariate Probit Equations for the Probability of Regular Primary Care and the Probability of Blood Pressure Control (Year and quarter fixed effects are not shown).

\begin{tabular}{|c|c|c|c|c|c|c|}
\hline \multirow[b]{2}{*}{ Variable } & \multicolumn{3}{|c|}{$\begin{array}{c}\text { Probability of Regular } \\
\text { Primary Care }\end{array}$} & \multicolumn{3}{|c|}{$\begin{array}{l}\text { Probability of Blood } \\
\text { Pressure Control }\end{array}$} \\
\hline & $\begin{array}{l}\text { Coefficient } \\
\qquad(\Delta z)\end{array}$ & $\begin{array}{c}P \\
\text { Value }\end{array}$ & $95 \% \mathrm{CI}$ & $\begin{array}{l}\text { Coefficient } \\
\qquad(\Delta z)\end{array}$ & $\begin{array}{c}P \\
\text { Value }\end{array}$ & $95 \% \mathrm{CI}$ \\
\hline \multicolumn{7}{|l|}{ Demographics } \\
\hline Age & 0.027 & $.000^{* * *}$ & $0.021-0.033$ & -0.029 & $.000^{* * *}$ & -0.034 to -0.023 \\
\hline Female sex & 0.088 & $.000^{* * *}$ & $0.055-0.120$ & 0.047 & $.001^{* *}$ & $0.019-0.075$ \\
\hline \multicolumn{7}{|l|}{ Diabetes mellitus } \\
\hline Duration & 0.062 & .359 & -0.070 to 0.194 & 0.005 & .401 & -0.017 to 0.007 \\
\hline Duration $\times$ age & 0.019 & .524 & -0.040 to 0.078 & 0.000 & .185 & $0.000-0.000$ \\
\hline Diagnosed & -0.007 & .322 & -0.022 to 0.007 & 0.217 & $.001^{* *}$ & $0.093-0.341$ \\
\hline Identified from registry & 0.000 & $.003^{* *}$ & -0.001 to 0.000 & 0.102 & $.000^{* * *}$ & $0.051-0.153$ \\
\hline Duration $\times$ registry & 0.029 & $.000^{* * *}$ & $0.020-0.037$ & -0.014 & $.000^{* * *}$ & -0.021 to -0.006 \\
\hline \multicolumn{7}{|l|}{ Risk factors } \\
\hline Insulin prescribed & 0.213 & $.000^{* * *}$ & $0.177-0.249$ & 0.045 & $.005^{* *}$ & $0.013-0.076$ \\
\hline High LDL diagnosed & 0.275 & $.000^{* * *}$ & $0.226-0.324$ & -0.193 & $.000^{* * *}$ & -0.239 to -0.147 \\
\hline $\mathrm{BMI}$ & -0.087 & $.000^{* * *}$ & -0.116 to -0.057 & -0.047 & $.000^{* * *}$ & -0.068 to -0.026 \\
\hline Excess BMI & 0.121 & $.000^{* * *}$ & $0.091-0.150$ & -0.005 & .657 & -0.016 to 0.026 \\
\hline $\mathrm{BMI} \times$ age & 0.000 & $.000^{* * *}$ & -0.001 to 0.000 & 0.001 & $.000^{* * *}$ & $0.000-0.001$ \\
\hline Hypertension index $^{\dagger}$ & & & & -0.239 & $.000^{* * *}$ & -0.255 to -0.223 \\
\hline Blood pressure index ${ }^{\ddagger}$ & -0.025 & $.000^{* * *}$ & -0.033 to -0.018 & - & - & - \\
\hline Tobacco smoker & -0.152 & $.000^{* * *}$ & -0.186 to -0.119 & 0.049 & $.001^{* *}$ & $0.019-0.078$ \\
\hline Smokeless tobacco user & 0.198 & $.000^{* * *}$ & $0.146-0.250$ & -0.013 & .556 & -0.029 to 0.054 \\
\hline \multicolumn{7}{|l|}{ Access } \\
\hline Matanuska-Susitna borough resident & -0.653 & $.000^{* * *}$ & -0.706 to -0.601 & - & - & - \\
\hline Outside service area & -0.078 & $.010^{*}$ & -0.137 to -0.019 & - & - & - \\
\hline Miles to primary care & -0.010 & $.000^{* * *}$ & -0.012 to -0.007 & 0.000 & $.000^{* * *}$ & $0.000-0.000$ \\
\hline \multicolumn{7}{|l|}{ Primary care } \\
\hline Nutrition/exercise classes (instrument) & - & - & - & 0.022 & $.001^{* *}$ & $0.009-0.035$ \\
\hline Regular primary care & - & - & - & 0.702 & $.000^{* * *}$ & $0.473-0.930$ \\
\hline Constant & 2.238 & $.000^{* * *}$ & $1.458-3.018$ & 1.421 & $.000^{* * *}$ & $0.809-2.034$ \\
\hline \multicolumn{7}{|l|}{ Summary statistics } \\
\hline$\rho$ & -0.306 & $.000^{* * *}$ & - & - & - & - \\
\hline Log likelihood & $-39,783$ & - & - & - & - & - \\
\hline Wald $\chi^{2}(70)$ & 4,656 & $.000^{* * *}$ & - & - & - & - \\
\hline Observations & 39,504 & - & - & - & - & - \\
\hline
\end{tabular}

${ }^{*} P<.05 ;{ }^{* *} P<.01 ;{ }^{* * *} P<.001$

${ }^{\dagger}$ Hypertension index, derived from blood pressure measured during the initial encounter: 0 if systolic blood pressure (SBP) $<120$ and diastolic blood pressure $(\mathrm{DBP})<80 ; 1$ if $120 \leq \mathrm{SBP}<140$ or $80 \leq \mathrm{DBP}<90 ; 2$ if $140 \leq \mathrm{SBP}<160$ or $90 \leq \mathrm{DBP}<100 ; 3$ if $\mathrm{SBP}$ $\geq 160$ or $\mathrm{DBP} \geq 100$.

${ }^{\ddagger}$ Blood pressure index, derived from blood pressure measured during the initial encounter: (SBP - 100)/20 + (DBP - 70)/10.

BMI, body mass index; CI, confidence interval; LDL, low-density lipoprotein.

half had high blood pressure, and slightly more than half smoked or used smokeless tobacco at baseline. In addition, $22 \%$ were prescribed insulin. The mean number of encounters per quarter of observations was 2.6 , and $78 \%$ of quarterly encounter records met the criteria for RPC. The mean time interval between successive HbA1c measurements exceeded 1 year, however, indicating that a substantial fraction of the population did not maintain the recommended level of screening; those who did not get RPC often went many years between HbA1c tests.

Figures 1 and 2 show the annual average rates of blood pressure control and glycemic control, respectively, among the cohort of customer-owners with DM (the binary outcomes to be explained). 
Table 3. Bivariate Probit Equations for the Probability of Regular Primary Care and the Probability of Glycemic Control (Year and quarter fixed effects are not shown).

\begin{tabular}{|c|c|c|c|c|c|c|}
\hline \multirow[b]{2}{*}{ Variables } & \multicolumn{3}{|c|}{$\begin{array}{c}\text { Probability of Regular } \\
\text { Primary Care }\end{array}$} & \multicolumn{3}{|c|}{$\begin{array}{l}\text { Probability of } \\
\text { Glycemic Control }\end{array}$} \\
\hline & $\begin{array}{l}\text { Coefficient } \\
\qquad(\Delta z)\end{array}$ & $\begin{array}{c}P \\
\text { Value }\end{array}$ & $95 \% \mathrm{CI}$ & $\begin{array}{l}\text { Coefficient } \\
\quad(\Delta z)\end{array}$ & $\begin{array}{c}P \\
\text { Value }\end{array}$ & $95 \% \mathrm{CI}$ \\
\hline \multicolumn{7}{|l|}{ Demographics } \\
\hline Age & 0.026 & $0.000^{* * *}$ & $0.020-0.033$ & -0.016 & $0.000^{* * *}$ & -0.022 to -0.010 \\
\hline Female sex & 0.077 & $0.000^{* * *}$ & $0.044-0.109$ & 0.031 & $0.040^{*}$ & $0.001-0.060$ \\
\hline \multicolumn{7}{|l|}{ Diabetes mellitus } \\
\hline Identified from registry & 0.025 & 0.393 & -0.032 to 0.081 & 0.206 & $0.000^{* * *}$ & $0.154-0.258$ \\
\hline Duration & -0.008 & 0.259 & -0.023 to 0.006 & -0.043 & $0.000^{* * *}$ & -0.057 to -0.030 \\
\hline Duration $\times$ age & -0.0003 & $0.003^{* *}$ & -0.0005 to -0.0001 & 0.0005 & $0.000^{* * *}$ & $0.0003-0.0007$ \\
\hline Duration $\times$ registry & 0.029 & $0.000^{* * *}$ & $0.021-0.037$ & -0.017 & $0.000^{* * *}$ & -0.024 to -0.010 \\
\hline \multicolumn{7}{|l|}{ Risk factors } \\
\hline Insulin prescribed & 0.226 & $0.000^{* * *}$ & $0.190-0.262$ & -0.438 & $0.000^{* * *}$ & -0.469 to -0.406 \\
\hline High LDL diagnosis & 0.281 & $0.000^{* * *}$ & $0.231-0.331$ & -0.100 & $0.000^{* * *}$ & -0.154 to -0.047 \\
\hline $\mathrm{BMI}$ & -0.090 & $0.000^{* * *}$ & -0.120 to -0.061 & -0.030 & $0.009^{* * *}$ & -0.052 to -0.007 \\
\hline Excess BMI & 0.124 & $0.000^{* * *}$ & $0.094-0.154$ & -0.003 & 0.804 & -0.026 to 0.020 \\
\hline $\mathrm{BMI} \times$ age & -0.0005 & $0.000^{* * *}$ & -0.0006 to -0.0003 & 0.0006 & $0.000^{* * *}$ & $0.0005-0.0008$ \\
\hline Blood pressure index & -0.023 & $0.000^{* * *}$ & -0.031 to -0.015 & -0.018 & $0.000^{* * *}$ & -0.025 to -0.011 \\
\hline Tobacco smoker & -0.154 & $0.000^{* * *}$ & -0.187 to -0.120 & 0.018 & $0.286^{* * *}$ & -0.015 to 0.050 \\
\hline Smokeless tobacco user & 0.211 & $0.000^{* * *}$ & $0.159-0.264$ & 0.004 & 0.869 & -0.043 to 0.050 \\
\hline \multicolumn{7}{|l|}{ Access } \\
\hline Matanuska-Susitna borough resident & -0.078 & $0.011^{*}$ & -0.138 to -0.018 & 0.177 & $0.000^{* * *}$ & $0.130-0.224$ \\
\hline Outside service area & -0.644 & $0.000^{* * *}$ & -0.698 to -0.590 & -0.258 & $0.000^{* * *}$ & -0.353 to -0.164 \\
\hline Miles to primary care & -0.010 & $0.000^{* * *}$ & -0.012 to -0.008 & - & - & - \\
\hline \multicolumn{7}{|l|}{ Primary care } \\
\hline Regular primary care & - & - & - & 1.163 & $0.000^{* * *}$ & $0.813-1.513$ \\
\hline Constant & 2.404 & $0.000^{* * *}$ & $1.627-3.180$ & -0.297 & 0.393 & -0.978 to 0.384 \\
\hline \multicolumn{7}{|l|}{ Summary statistics } \\
\hline$\rho$ & -0.338 & $0.004^{* *}$ & - & - & - & - \\
\hline Log likelihood & $-36,102$ & & - & - & - & - \\
\hline Wald $\chi^{2}(70)$ & 5,041 & $0.000^{* * *}$ & - & - & - & - \\
\hline Observations & 38,889 & & - & - & - & - \\
\hline
\end{tabular}

${ }^{*} P<.05 ;{ }^{* *} P<.01 ;{ }^{* * *} P<.001$

${ }^{\dagger}$ Blood pressure index, derived from blood pressure measured during the initial encounter: (systolic pressure -100$) / 20+($ diastolic pressure -70$) / 10$.

BMI, body mass index; CI, confidence interval; LDL, low-density lipoprotein.

Table 2 displays the results of the bivariate probit equation to explain blood pressure control along with RPC at the lower threshold (130/80 $\mathrm{mmHg})$. Results of analogous equations estimated with the higher blood pressure threshold $(140 / 90 \mathrm{mmHg})$ and with a threshold changing from the higher to the lower level in 2004 were similar (data not shown). Table 3 shows the respective bivariate probit equation for glycemic control. Typical for bivariate probit regression, both tables display the coefficients $(\Delta z)$ for the 2 equations that have been jointly estimated to adjust for the correlation be- tween the 2 dependent variables (RPC and the health outcome). As an explanatory variable and with the correlation addressed, RPC is significantly associated with an increased likelihood of blood pressure control $(\Delta z=0.702 ; P<.001)$ and an increased likelihood of glycemic control $(\Delta z=$ $1.163 ; P<.001)$. The effects are quite large in both instances: At the sample mean, these $z$ score changes for RPC represent relative risks (Figure 3) of 1.89 (95\% confidence interval [CI], 1.59-2.18) and 2.77 (95\% CI, 2.23-3.22), respectively, and numbers needed to treat of 6 (95\% CI, 5-8) and 5 
Figure 3. Relative risk at sample means of blood pressure control and glycemic control with regular primary care. Error bars represent $95 \%$ confidence intervals.

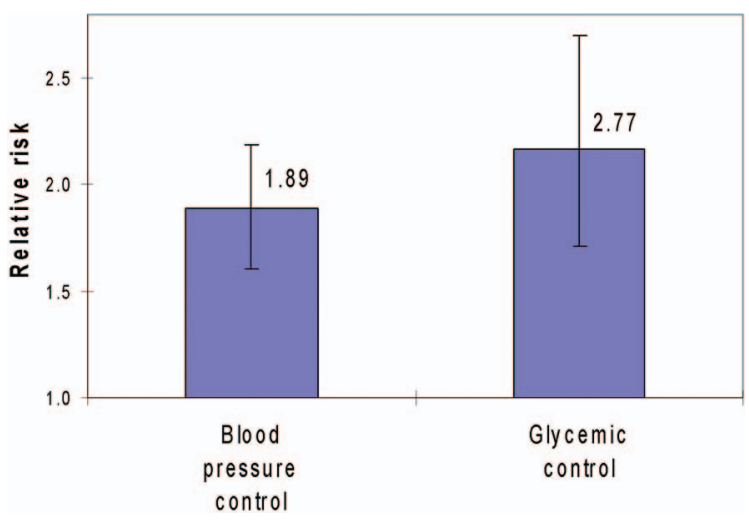

(95\% CI, 5-6), respectively. Higher attendance at nutrition and exercise classes also significantly increased blood pressure control $(P=.001)$. On average, taking 10 classes increased the $z$ score for blood pressure control by 0.22 , representing a relative risk of 1.25 (95\% CI, 1.10-1.41) and a number needed to treat of 14 (95\% CI, 7-33).

Many of the risk factors for complicationshigh low-density lipoprotein, prescribed insulin, more overweight, higher blood pressure, smokeless tobacco user-were significantly associated with a higher likelihood of RPC $(P<.001)$. However, tobacco smokers were less likely to obtain RPC $(P<.001)$. All measures of reduced access were negatively associated with RPC: living in the Matanuska-Susitna borough, where public transportation is limited $(P<.01)$; miles to the nearest primary care clinic $(P<.001)$; and residing outside the service area $(P<.001)$. At the mean rate of RPC, moving 10 miles farther away reduced that probability by $3.7 \%$ (relative risk, $0.963 ; 95 \% \mathrm{CI}$, 0.954-0.971) in both the blood pressure control and glycemic control equations.

Tables 2 and 3 show significant negative correlation coefficients $(\rho)$ between RPC and blood pressure control $(P<.05)$ and between RPC and glycemic control $(P<.01)$, respectively. This suggests that unobserved factors associated with customerowners seeking primary care were associated with worse outcomes for these 2 risk factors for DM complications.

The significant associations found between RPC and both blood pressure control and glycemic control represent relative effects in a given year. An- nual intercepts estimated in the bivariate probit models (data not shown) reveal general changes in outcomes and primary care utilization over time, adjusting for other relevant factors; they provide an opportunity to test whether blood pressure control and glycemic control changed during the study period. The adjusted rate of blood pressure control measured by these intercepts increased by $42.6 \%$ (standard error, $4.5 \% ; P<.001$ ) between the time period before PCMH implementation (19961999) and after the new model was well established (2005-2010). A similar comparison for glycemic control showed a $49.3 \%$ increase (standard error, $4.7 \% ; P<.001$ ). The relatively small population provides insufficient statistical power to test formally whether the improved outcomes came about gradually or immediately, but casual inspection of the intercepts shows an abrupt change right after the PCMH model was introduced.

\section{Discussion}

The effect of primary care utilization on health outcomes can be difficult to perceive given the relationship between utilization and outcomes. While there have been studies of the effects of improved access and other PMCH components on health outcomes, ${ }^{4,8-14}$ to our knowledge none of these addressed the potential bias introduced from the voluntary decision to seek primary care services either before or after PCMH implementation. In this study we addressed this bias statistically and saw a positive effect of RPC utilization on 2 important risk factors for complications of DM: high blood pressure and poor glycemic control. While the results applied specifically to the AI/AN study population, we see no reason to doubt their applicability to other populations.

In a finding contrary to ours, Harris ${ }^{25,26}$ found no association between primary care utilization or access and health outcomes for adults with DM in a US health surveillance study. Harris did not, however, take into account the potential nonrandom selection effect from voluntary primary care, whereas we did. That difference in methods may explain why our findings differ.

While the primary question in this study did not focus on implementation of PCMH components at SCF, findings align with expectations of proponents of the model. In addition to the positive effect on blood pressure control associated with attending 
education classes introduced by SCF, we observed higher rates of primary care utilization and higher rates of glycemic control and blood pressure control after the implementation of other PCMH components. Although it is possible that these results reflect only secular trends, specific PCMH features, including increased access to primary care, improved continuity and coordination of care, and increased cultural awareness and customer focus of the health care system, may have played a role. ${ }^{27}$

We found that reduced access as measured by the distance to services was associated with decreased RPC utilization, indicating that access is an important aspect of the PCMH model of care, as indicated by other studies. ${ }^{3,13}$ In addition, people with more risk factors were more likely to have RPC, and some had poor health outcomes despite RPC because of factors that were not measured in this study. It is possible that these individuals had comorbid conditions, causing them to have higher service utilization but difficulty controlling their DM health outcomes.

There are some limitations to this study. All data used in this study are from electronic health and billing records created for reasons other than research and that had unknown reliability over the study period. The availability of electronic records limits observations before PCMH implementation to a relatively brief 5 -year period. Further, the results of our study take into account only the immediate effect of RPC on blood pressure control and glycemic control. Effects of RPC that may manifest more than 1 year into the future are not measured in this study. Other changes not related to primary care utilization over the study period have affected the health outcomes for this cohort, including aging of the cohort, improved access to nonprimary care health services over the study period, and improved guidelines and health care technologies for people with DM in general.

In this study we observed an association between regular primary care utilization and improved health outcomes (specifically, higher rates of blood pressure control and glycemic control) for adult customer-owners with DM in a tribally operated managed care program. Customer-owners with better access, measured by closer distance to primary care services, had a better likelihood of improved outcomes. These findings take into account potential bias arising from voluntarily seeking primary care services.
The authors acknowledge Mike Mosley for querying the electronic health records and providing expertise on health indicators.

\section{References}

1. Standards of medical care in diabetes-2013. Diabetes Care 2013;36(Suppl 1):S11-66.

2. Wu CX, Tan WS, Toh MP, Heng BH. Stratifying healthcare costs using the Diabetes Complication Severity Index. J Diabetes Complications. 2012;26: 107-12.

3. Hossain WA, Ehtesham MW, Salzman GA, Jenson R, Calkins CF. Healthcare access and disparities in chronic medical conditions in urban populations. South Med J 2013;106:246-54.

4. Jortberg BT, Miller BF, Gabbay RA, Sparling K, Dickinson WP. Patient-centered medical home: how it affects psychosocial outcomes for diabetes. Curr Diabetes Rep 2012;12:721-8.

5. Standards for patient-centered medical home (PCMH), 2011. Washington, DC: National Committee for Quality Assurance; 2011.

6. Arar NH, Noel PH, Leykum L, Zeber JE, Romero $\mathrm{R}$, Parchman ML. Implementing quality improvement in small, autonomous primary care practices: implications for the patient-centred medical home. Qual Prim Care 2011;19:289-300.

7. Kent D, D'Eramo Melkus G, Stuart PM, et al. Reducing the risks of diabetes complications through diabetes self-management education and support. Popul Health Manag 2013;16:74-81.

8. Solberg LI, Asche SE, Fontaine P, Flottemesch TJ, Anderson LH. Trends in quality during medical home transformation. Ann Fam Med 2011;9:515-21.

9. Bojadzievski T, Gabbay RA. Patient-centered medical home and diabetes. Diabetes Care 2011;34: 1047-53.

10. Schouten LM, Hulscher ME, van Everdingen JJ, Huijsman R, Niessen LW, Grol RP. Short- and long-term effects of a quality improvement collaborative on diabetes management. Implement Sci 2010;5:94.

11. Kirsh S, Hein M, Pogach L, et al. Improving outpatient diabetes care. Am J Med Qual 2012;27:233-40.

12. Isetts BJ, Brummel AR, de Oliveira DR, Moen DW. Managing drug-related morbidity and mortality in the patient-centered medical home. Med Care 2012; 50:997-1001.

13. Lee K, Palacio C, Alexandraki I, Stewart E, Mooradian AD. Increasing access to health care providers through medical home model may abolish racial disparity in diabetes care: evidence from a cross-sectional study. J Natl Med Assoc 2011;103:250-6.

14. Patient-Centered Primary Care Collaborative. Practices in the spotlight: the medical home and diabetes care. 2011. Available from: http://www.pcpcc.org/ 
sites/default/files/media/diabetes_guide_2011.pdf. Accessed November 6, 2014.

15. Eby DK. Primary care at the Alaska Native Medical Center: a fully deployed "new model" of primary care. Int J Circumpolar Health 2007;66(Suppl 1): 4-13.

16. Driscoll DL, Hiratsuka V, Johnston JM, et al. Process and outcomes of patient-centered medical care with Alaska Native people at Southcentral Foundation. Ann Fam Med 2013;11(Suppl 1):S41-9.

17. Disparities factsheet. Rockville (MD): US Indian Health Service. Available from: http://www.ihs.gov/ newsroom/factsheets/disparities/. Accessed June 30, 2014.

18. Alaska Native Tribal Health Consortium. Anchorage and Mat-Su Regional Health Profile. Anchorage: Alaska Native Tribal Health Consortium; 2011.

19. Wilson C, Gilliland S, Cullen T, et al. Diabetes outcomes in the Indian health system during the era of the Special Diabetes Program for Indians and the Government Performance and Results Act. Am J Public Health 2005;95:1518-22.

20. Ramesh M, Schraer C, Mayer AM, Asay E, Koller K. Effect of special diabetes program for Indians funding on system changes in diabetes care and outcomes among American Indian/Alaska Native people 1994-2004. Int J Circumpolar Health 2008;67:203-12.
21. Jiang L, Beals J, Zhang L, et al. Latent class analysis of stages of change for multiple health behaviors: results from the Special Diabetes Program for Indians Diabetes Prevention Program. Prev Sci 2012;13: 449-61.

22. Arauz-Pacheco C, Parrott MA, Raskin P; American Diabetes Association. Hypertension management in adults with diabetes. Diabetes Care 2004;27(Suppl 1):S65-7.

23. Indian Health Service, Department of Health and Human Services. IHS Clinical Reporting System: National GPRA Developmental Report version 10.0. Albuquerque (NM): Office of Information Technology, Division of Information Resource Management; 2010.

24. Brookhart MA, Rassen JA, Schneeweiss S. Instrumental variable methods in comparative safety and effectiveness research. Pharmacoepidemiol Drug Saf 2010;19:537-54.

25. Harris MI. Health care and health status and outcomes for patients with type 2 diabetes. Diabetes Care 2000;23:754-8.

26. Harris MI. Racial and ethnic differences in health care access and health outcomes for adults with type 2 diabetes. Diabetes Care 2001;24:454-9.

27. Beach MC, Saha, S, Cooper, L. The role and relationship of cultural competence and patient-centeredness in health care quality. New York: The Commonwealth Fund; 2006. 